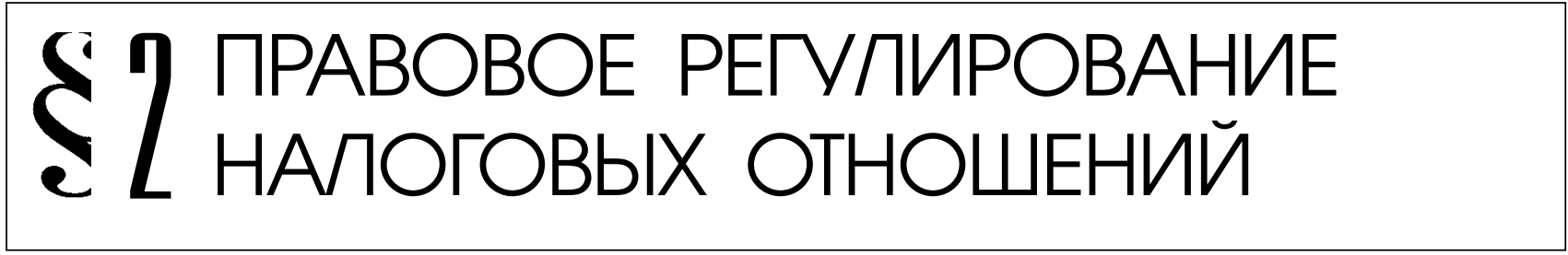

А.А. Гараев

\title{
УДЕРЖАНИЕ ТАМОЖЕННЫХ ПОШЛИН, НАЛОГОВ С СУММ, ПОЛУЧЕННЫХ ОТ РЕАЛИЗАЦИИ ТОВАРОВ, ЗАДЕРЖАННЫХ ТАМОЖЕННЫМИ ОРГАНАМИ
}

\begin{abstract}
Аннотация: Рассмотрены нестыковки правовых норм, регулирующих вопросы распределения денежных средств, полученных от реализации товаров, задержанных таможенными органами. Из денежных средств, полученных от реализации задержанных товаров, подлежат удержанию, в первую очередь, таможенные пошлины и налоги, во вторую очередь, расходы, связанные с их хранением и реализацией. Оставшаяся сумма подлежит возврату декларанту, собственнику товара. Существующие нормы законодательства, определяющие порядок распоряжения (реализация, уничтожение) задержанными товарами, учитывают не все обстоятельства, при которых правоприменителю необходимо принимать решение о способе распоряжения и распределения денежных средств. Приведены примеры, когда одни нормы права, регулирующие данные отношения, противоречат другим нормам. Высказаны предложения по преодолению данных коллизий. Для анализа имеющихся противоречий в правовых нормах рассмотрены причины образования невостребованных товаров, находящихся под таможенным контролем и в последующем задерживаемых таможенными органами. Приведены примеры задержания товаров по различным основаниям. Для изучения оснований задержания товаров предложено классифицировать их задержание по экономическим и административным причинам. Впервые предложена классификация причин образования товаров, задержанных таможенными органами, позволяющая найти способы преодоления коллизий правовых норм. Исходя из предложенной классификации, выявлено, что существующий порядок правового регулирования частично подходит только для осуществления распоряжения товарами, задержанными по экономической причине. При задержании товаров по административным причинам, правовые нормы по распоряжению задержанными товарами, удержанию таможенных пошлин и налогов вступают в противоречие с нормами, содержащимися в других институтах таможенного и налогового права и поэтому не позволяют удержать таможенные пошлины и налоги с сумм, полученных от реализации задержанных товаров.
\end{abstract}

Ключевые слова: недоимка, запреты, реализация товара, таможенная пошлина, задолженность, налог, распоряжение товаром, удержание пошлины, выпуск товара, задержание товара.

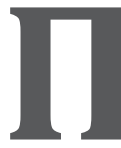
ри осуществлении таможенного оформления товары, находящиеся под таможенным контролем, помещаются на склады временного хранения.
Срок временного хранения товаров не может превышать четырех месяцев. В случае превышения установленного срока временного хранения товары задерживаются тамо- 
женным органом. Поэтому в большинстве случаев товары, задержанные таможенными органами - это невостребованные товары, находящиеся под таможенным контролем. Процедуру задержания товаров, а также порядок дальнейшего распоряжения ими определяют Таможенный кодекс Таможенного союза (ТКТС) ${ }^{1}$ и законодательство государств - членов Таможенного союза. Общий порядок задержания и дальнейшего распоряжения задержанными товарами определены в ст. 189, 190 и 192 федерального закона «0 Таможенном регулировании в Российской Федерации» ${ }^{2}$. Данные нормы в настоящий момент не имеют практики применения. Однако, уже сейчас видны не стыковки и противоречия в правовых актах по этой процедуре, мешающие практике применения данных норм.

Задержанные таможенным органом товары продолжают оставаться в собственности лица в соответствии с условиями внешнеэкономической сделки. Именно поэтому в случае реализации задержанных товаров остаток денежных средств после вычета сумм таможенных пошлин, налогов и расходов по хранению и реализации этих товаров подлежит возврату декларанту, собственнику или законному владельцу товара. Другое дело, если происходит уничтожение задержанного товара. В этом случае собственник лишается имущества, в отношении которого он своевременно не предпринял действий по распоряжению.

В соответствии с п. 3 ст. 148 ТКТС товары, расходы по хранению и реализации которых превышают их стоимость, а также в других случаях, предусмотренных за-

\footnotetext{
1 Таможенный кодекс Таможенного союза // Собрание законодательства РФ. 2010. № 50. Ст. 6615.

2 Федеральный закон от 27.11.2010 № 311-Ф3 «О таможенном регулировании в Российской Федерации» // Собрание законодательства РФ. 2010. № 48. Ст. 6252.
}

конодательством государства - члена таможенного союза, таможенным органом которого задержаны товары, подлежат уничтожению, если иное не установлено законодательством этого государства члена таможенного союза. Таким образом, условие, при котором может происходить уничтожение задержанных товаров, определяется ТКТС или национальным законодательством. В Российском таможенном законе условием уничтожения задержанных товаров названо превышение стоимости расходов по хранению и реализации товаров над их рыночной стоимостью (ч. 13 ст. 190 ФЗ «0 таможенном регулировании в РФ»). По сути, была повторена норма, содержащаяся в ТКТС без добавления новых условий. Однако, при определении условий уничтожения задержанных товаров разработчики закона не учли очень важный фактор - наличие других сумм, подлежащих удержанию с реализованного задержанного товара и очередность возмещения расходов по реализации и хранению. В соответствии с п. 1 ст. 149 ТКТС, в первую очередь из сумм, полученных от реализации задержанных товаров, удерживаются таможенные пошлины, налоги и только во вторую очередь расходы, связанные с транспортировкой, хранением и реализацией этих товаров.

Для прогнозирования распределения сумм, полученных от реализации задержанных товаров, важно проанализировать причины появления задержанных товаров. Участник внешнеэкономической деятельности (ВЭД) перемещает коммерческий товар через границу для того чтобы его продать. Следовательно, он заинтересован чтобы товар был выпущен таможенным органом и продан. Однако, при перемещении товаров через таможенную границу собственником или декларантом не всегда 
учитываются все факторы и действующие нормы законодательства. Поэтому могут возникнуть непредвиденные обстоятельства, при которых товар не будет выпущен.

Выпуск товара становится не выгоден собственнику, если стоимость аналогичных товаров, находящихся на рынке, куда будет выпущен товар, ниже стоимости товара после его таможенной очистки. Такая ситуация может возникнуть если таможенная стоимость товара плюс сумма подлежащих уплате таможенных пошлин, налогов значительно выше рыночной стоимости товара. В этом случае затраты участника ВЭД по покупке, перевозке товара (как правило уже оплаченного) и оплате таможенных пошлин, налогов (происходит при выпуске товара таможенным органом) не компенсируются суммой, которую он получит от продажи товара. В этом случае участник ВЭД может заявить иную таможенную процедуру (например, реэкспорт).

В отдельных случаях, из-за небольшого размера партии товаров и, следовательно, незначительных потерях участник ВЭД бросает товар и не производит его таможенное оформление.

Другой причиной задержания товара может быть не желание участника ВЭД осуществлять выпуск товара, если он помещен на хранение не в регионе деятельности участника ВЭД и для выпуска товара необходимо подавать декларацию таможенному органу по месту нахождения товара (обычно такое бывает после решения о возврате товара, проходившего по делу об административном правонарушении или уголовному делу). Это требует временных и материальных затрат, которые не окупятся при дальнейшей продажи товара. С активным внедрением в таможенных органах технологии удаленного выпуска товара (когда место документального и фак- тического контроля различаются) таких случаев становится меньше. Однако, эта причина продолжает оставаться актуальной для выпуска товаров, перемещаемых физическими лицами, где технология удаленного выпуска не применяется.

Описанные выше причины образования задержанных товаров имеют общее основание - экономическая нецелесообразность таможенного декларирования. Поэтому назовем данную группу причин задержания товаров экономической.

Помимо экономических причин существуют и иные причины задержания товаров, не связанные с необходимость увеличения затрат денежных средств на выпуск товара - назовем их административными. Рассмотрим административные причины подробнее.

Одним из оснований задержания товаров является невозможность перемещения через таможенную границу товаров, запрещенных или ограниченных к ввозу или вывозу. Например, на территорию Таможенного союза ввезли товар, запрещенный к ввозу. На основании ст. 152 ТКТС такие товары подлежат немедленному вывозу, причем для такого вывоза необходимо согласие другой стороны и государства, куда возвращается товар (в том государстве разрешен вывоз такого товара, но обратный ввоз запрещен). Такая ситуация может возникнуть при перемещении опасных или радиоактивных отходов. К сожалению, в этом случае государство член Таможенного союза, где задержали запрещенный товар, обязано брать на себя организацию по уничтожению, захоронению или иному распоряжению опасными и радиоактивными отходами и возмещению возникающих расходов.

Другой административной причиной задержания товаров является применение запретов и ограничений к перемещаемых 
через таможенную границу товаров. В соответствии со ст. 4 ТКТС запреты и ограничения - это комплекс мер, применяемых в отношении товаров, перемещаемых через таможенную границу, включающий меры нетарифного регулирования, меры, затрагивающие внешнюю торговлю товарами и вводимые исходя из национальных интересов, особые виды запретов и ограничений внешней торговли товарами, меры экспортного контроля, в том числе в отношении продукции военного назначения, технического регулирования, а также санитарно-эпидемиологические, ветеринарные, карантинные, фитосанитарные и радиационные требования, которые установлены международными договорами государств - членов таможенного союза, решениями Комиссии таможенного союза и нормативными правовыми актами государств - членов таможенного союза, изданными в соответствии с международными договорами государств - членов таможенного союза. Т.е. для осуществления выпуска таких товаров необходимо представление специальных документов, с наличием которых возможно соблюдение заявленной таможенной процедуры. У участника ВЭД зачастую не имеется возможности получить эти документы, предъявить их таможенному органу и поэтому его товар задерживается. Приведем пример - обязательным условием выпуска транспортных средств является его соответствие техническим нормативам выбросов экологического класса (в настоящее время экологический стандарт «Евро 5») 3 .

Постановление Правительства РФ от 12.10.2005 № 609 «Об утверждении технического регламента «О требованиях к выбросам автомобильной техникой, выпускаемой в обращение на территории Российской Федерации, вредных (загрязняющих) веществ» // Собрание законодательства РФ. 2005. № 43. Ст. 4395.
Если экологический класс не соответствует установленным нормам, то и нельзя осуществить выпуск этого транспортного средства.

Таким образом, можно выделить две основные причины задержания товаров таможенными органами - экономическую и административную.

При наличии экономической причины задержания товара необходимо выбирать способ распоряжения товаров, исходя из баланса их рыночной стоимости по отношению к сумме таможенных пошлин, налогов, подлежащих уплате за них при выпуске для внутреннего потребления плюс расходы по транспортировке, хранению товаров и иные расходы, связанные с реализацией этих товаров.

Принятие Таможенного кодекса Таможенного союза было известным компромиссом между странами Таможенного союза, а некоторые нормы принимались в спешке, без детальной проработки. В частности 21 глава ТКТС была разработана на основе опыта Республики Беларусь ${ }^{4}$.

При создании норм ТКТС (п. 3 ст. 148) и федерального закона «0 таможенном регулировании в РФ» (ч. 13 ст. 190) это обстоятельство, как указано выше, не учли, т.к. единственным условием уничтожения задержанных товаров является превышение расходов по хранению и реализации товаров над их стоимостью.

Таким образом, возмещение расходов по хранению и реализации будет происходить из остатка сумм вырученных от реализации задержанных товаров (если они еще останутся) после удержания таможенных пошлин, налогов. Поэтому ре-

\footnotetext{
4 Гараев А.А. Распоряжение товарами по таможенному законодательству Республики Беларусь // Таможенное дело. 2011. № 2. С. 15-24.
} 
шение об уничтожении или реализации задержанного товара необходимо принимать исходя из суммы подлежащих уплате таможенных пошлин, налогов и расходов по транспортировке, хранению и реализации. Следовательно, при действующих нормах закона при реализации задержанных товаров достаточно часто будет возникать задолженность по уплате таможенных платежей, и (или) расходы по реализации будут не полностью погашены. Погашение образовавшейся задолженности должно осуществляться за счет декларанта (п. 3 ст. 148 ТКТС), что приведет к дополнительным спорам, т.к. реализация задержанного товара происходит без согласия декларанта, властными, административными методами.

По установленным нормам таможенного законодательства критерий уничтожения задержанных товары при превышении расходов по хранению и реализации товаров не подпадает задержание товаров по административным причинам. Если задержанные по административным причинам товары подлежат реализации, то нарушается базовый принцип равенства лиц, участвующих в реализации товаров. В данном случае государству можно запускать в экономический оборот (реализовывать) товары, в отношении которых действуют запреты и ограничения и на которые нет разрешительных документов, а участнику ВЭД это запрещено (именно поэтому его товар задержали).

Другим противоречием норм таможенного законодательства по процедуре удержания ввозных таможенных пошлин, налогов с задержанных товаров является предположение, что товары будут задерживаться только при их ввозе на таможенную территорию РФ. Согласно п. 1 ст. 149 ТКТС из сумм полученных от реализации задержанных товаров удерживаются суммы таможенных пошлин, налогов, которые подлежали бы уплате при помещении задержанных товаров под таможенную процедуру выпуска для внутреннего потребления (импорт товаров). Выпуск товаров для внутреннего потребления предполагает приобретение иностранными товарами статуса товаров таможенного союза (пп.37 п. 1 ст. 4 ТКТС).

Однако, задерживаться могут товары, перемещаемые через таможенную границу (ст. 152, 185, 192 ТКТС), куда в соответствии с пп. 22 п. 1 ст. 4 ТКТС входит ввоз товаров на таможенную территорию Таможенного союза или вывоз товаров с таможенной территории Таможенного союза. При экспорте товаров с территории Таможенного союза товары продолжают считаться товарами Таможенного союза до их фактического вывоза с таможенной территории Таможенного союза (п. 1 ст. 212 и п. 2 ст. 213 ТКТС). Выглядит нелогичной и противоречивой всему остальному таможенному законодательству норма по необходимости удержания с товаров Таможенного союза суммы таможенных пошлин, налогов как с ввозимых иностранных товаров. Более того, действующим налоговым законодательством при вывозе товаров предусмотрено даже не взимание, а возмещение налога на добавленного стоимость (ст. 165 НК Р $\Phi^{5}$ ).

Также таможенное законодательство не определяет как удерживать и надо ли удерживать таможенные платежи с сумм, полученных от реализации задержанных товаров, которые запрещены к ввозу на таможенную территорию. Такие товары запрещены к обороту на террито-

\footnotetext{
5 Налоговый кодекс Российской Федерации (часть вторая) от 05.08.2000 № 117-Ф3 // Собрание законодательства РФ. 2000. № 32. Ст. 3340.
} 
рии РФ и поэтому в приказе ФТС России от 12.08.2013 № 1510 предусмотрено, что «суммы подлежащих уплате таможенных платежей для товаров, запрещенных к ввозу не рассчитываются» ${ }^{6}$, предполагая, что данные товары должны уничтожаться. В то же время, как указывалось выше, п. 3 ст. 148 ТКТС не содержит оснований для уничтожения запрещенных к ввозу задержанных товаров и, следовательно, они могут реализовываться. Вопрос каким образом и в каком размере с запрещенных к реализации задержанных товаров будут удерживаться таможенные платежи, остается открытым.

Порядок возмещения расходов по хранению задержанных товаров должен устанавливаться Правительством РФ (ч. 4 ст. 202 Ф3 «0 таможенном регулировании в РФ»). Для возмещения расходов по хранению задержанных товаров, между таможенным органом и владельцем склада временного хранения должен быть заключен договор, в порядке, определяемом Правительством РФ (ч. 2 ст. 202 ФЗ «0 таможенном регулировании в РФ»). Учитывая, что в настоящее время Правительство РФ не определило порядок заключения договора по хранению задержанных товаров и порядок возмещения расходов по хранению, таможенные органы не могут определить сумму расходов по хранению задержанных товаров. Поэтому, выбор способа распоряжения товарами (реализация или уничтожение) в соответствии с ч. 13 ст. 190 ФЗ «0 таможенном регулировании в РФ» при отсутствии соответствующего акта Правительства РФ не может применяться.

\footnotetext{
6 Приказ ФТС России от 12.08.2013 № 1510 «Об утверждении Порядка действий должностных лиц таможенных органов при осуществлении задержания товаров и документов на них, которые не являются предметами административных правонарушений или преступлений».
}

При уничтожении задержанного имущества остается законодательно не определенной процедура списания задолженности по таможенным пошлинам, налогам. пеням в отношении этого имущества. Ocнования для прекращения обязанности по уплате таможенных платежей определены в п. 2 ст. 80 ТКТС. Среди этих оснований не определено уничтожение задержанных товаров. Получается, что задержанное имущество уничтожено, его нет, а задолженность по уплате таможенных платежей за этот товар числится за декларантом, собственником, законном владельцем. Это не совсем корректно и справедливо, т.к. таможенный орган своими властными действиями не только инициировал уничтожение собственности другого лица (эти действия в рамках закона), но и сделал декларанта должником перед бюджетом по таможенным пошлинам, налогам.

Таким образом, нестыковки правовых норм по распоряжению задержанными товарами возникли из-за недостаточной проработанности этого вопроса законодателем, а сама процедура нуждается корректировке. Полагаем, что для устранения существующих противоречий необходимо двигаться в сторону закрепления в правовых нормах уничтожения как единственного способа распоряжения задержанными товарами, причем санкционировать уничтожение должен суд. Это позволит избежать споров о конституционности распоряжения задержанными товарами и ограничит возможность злоупотреблений при их реализации. Кроме того, необходимо дополнить п. 2 ст. 80 ТКТС дополнительным основанием для прекращения обязанности по уплате таможенных пошлин и налогов - уничтожение задержанного товара. 


\section{Библиография:}

1. Таможенный кодекс Таможенного союза // Собрание законодательства РФ. 2010. № 50. Ст. 6615.

2. Федеральный закон от 27.11.2010 № 311-Ф3 «О таможенном регулировании в Российской Федерации» // Собрание законодательства РФ. 2010. № 48. Ст. 6252.

3. Постановление Правительства РФ от 12.10.2005 № 609 «Об утверждении технического регламента «О требованиях к выбросам автомобильной техникой, выпускаемой в обращение на территории Российской Федерации, вредных (загрязняющих) веществ» // Собрание законодательства РФ. 2005. № 43. Ст. 4395.

4. Гараев А.А. Распоряжение товарами по таможенному законодательству Республики Беларусь // Таможенное дело. 2011. № 2. С. 15-24.

5. Налоговый кодекс Российской Федерации (часть вторая) от 05.08.2000 № 117-Ф3 // Собрание законодательства РФ. 2000. № 32. Ст. 3340.

6. Приказ ФТС России от 12.08.2013 № 1510 «Об утверждении Порядка действий должностных лиц таможенных органов при осуществлении задержания товаров и документов на них, которые не являются предметами административных правонарушений или преступлений».

7. Ефремова Т.А. Налоговое администрирование в России: предпосылки становления и особенности функционирования // NB: Финансовое право и управление. - 2013. 2. - C. 1-23. DOI: 10.7256/2306-4234.2013.2.622. URL: http://www.e-notabene.ru/flc/ article_622.html

8. Агузарова Ф.С. Некоторые вопросы модернизации налоговой системы Российской Федерации // NB: Финансовое право и управление. - 2013. - 2. - С. 24-44. DOI: 10.7256/2306-4234.2013.2.629. URL: http://www.e-notabene.ru/flc/article_629.html

9. Костенников М.В., Корзун С.Ю., Трегубова Е.В. Административные запреты и механизмы защиты прав налогоплательщиков - физических лиц (часть 2) // Административное и муниципальное право. - 2010. - 3. - С. 5-33.

10. Ефремова Т.А., Ефремова Л.И. Информационно-технологические основы модернизации налогового администрирования / NB: Финансовоеправо иуправление. - 2012.1. - C. 212-236. URL: http://www.e-notabene.ru/flc/article_361.html

\section{References:}

1. Tamozhennyi kodeks Tamozhennogo soyuza // Sobranie zakonodatel'stva RF. 2010. № 50. St. 6615.

2. Federal'nyi zakon ot 27.11.2010 № 311-FZ «0 tamozhennom regulirovanii v Rossiiskoi Federatsii» // Sobranie zakonodatel’stva RF. 2010. № 48. St. 6252.

3. Postanovlenie Pravitel'stva RF ot 12.10.2005 № 609 «Ob utverzhdenii tekhnicheskogo reglamenta «O trebovaniyakh $\mathrm{k}$ vybrosam avtomobil'noi tekhnikoi, vypuskaemoi $\mathrm{v}$ obrashchenie na territorii Rossiiskoi Federatsii, vrednykh (zagryaznyayushchikh) veshchestv» // Sobranie zakonodatel'stva RF. 2005. № 43. St. 4395.

4. Garaev A.A. Rasporyazhenie tovarami po tamozhennomu zakonodatel'stvu Respubliki Belarus' // Tamozhennoe delo. 2011. № 2. S. 15-24. 
5. Nalogovyi kodeks Rossiiskoi Federatsii (chast' vtoraya) ot 05.08.2000 № 117-FZ / / Sobranie zakonodatel'stva RF. 2000. № 32. St. 3340.

6. Prikaz FTS Rossii ot 12.08.2013 № 1510 «Ob utverzhdenii Poryadka deistvii dolzhnostnykh lits tamozhennykh organov pri osushchestvlenii zaderzhaniya tovarov i dokumentov na nikh, kotorye ne yavlyayutsya predmetami administrativnykh pravonarushenii ili prestuplenii».

7. Efremova T.A. Nalogovoe administrirovanie v Rossii: predposylki stanovleniya i osobennosti funktsionirovaniya // NB: Finansovoe pravo i upravlenie. - 2013. - 2. - C. 1-23. DOI: 10.7256/2306-4234.2013.2.622. URL: http://www.e-notabene.ru/flc/article_622.html

8. Aguzarova F.S. Nekotorye voprosy modernizatsii nalogovoi sistemy Rossiiskoi Federatsii // NB: Finansovoe pravo i upravlenie. - 2013. - 2. - C. 24-44. DOI: 10.7256/23064234.2013.2.629. URL: http://www.e-notabene.ru/flc/article_629.html

9. Kostennikov M.V., Korzun S.Yu., Tregubova E.V. Administrativnye zaprety i mekhanizmy zashchity prav nalogoplatel'shchikov - fizicheskikh lits (chast' 2) // Administrativnoe i munitsipal'noe pravo. - 2010. - 3. - C. 5-33.

10. Efremova T.A., Efremova L.I. Informatsionno-tekhnologicheskie osnovy modernizatsii nalogovogo administrirovaniya // NB: Finansovoe pravo i upravlenie. - 2012. - 1. C. 212-236. URL: http://www.e-notabene.ru/flc/article_361.html 